Enl@ce: Revista Venezolana de Información, Tecnología y Conocimiento

ISSN: 1690-7515

Depósito legal pp 200402ZU1624

Año 4: No. 2, Mayo-Agosto 2007, pp. 101-102

\section{Implementing and Managing e-Government: An International Text}

Autor: Richard Heeks

ISBN 0761967915

Editorial: Sage Publications Ltd -2006-

Idioma: Inglés

Páginas 304

El profesor Richard Heeks, del Instituto para la Políticas y Gerencia del Desarrollo de la Universidad de Manchester, es un experto consultor de sistemas de información en la industria del software en la India.

El profesor Heeks nos presenta la obra Implementing and Managing eGovernment: An International Text que provee una cobertura bastante amplia de algunos tópicos asociados al desarrollo del gobierno electrónico (GE) y el rol de los gerentes y consultores en la planificación de estrategias para la construcción de sistemas asociados al GE. El libro abarca diversos aspectos que van desde la seguridad de los datos, hasta las cuestiones éticas asociadas al desarrollo de políticas que conllevan al diseño, construcción e implementación de sistemas de GE.

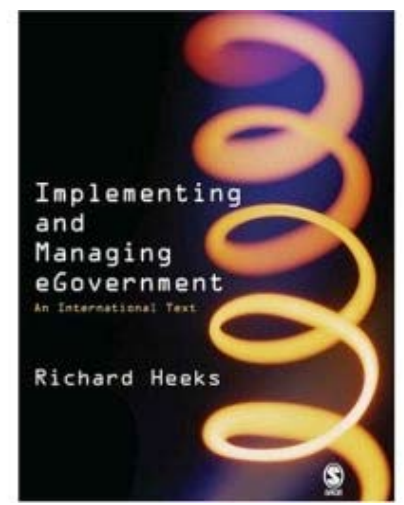

Con un enfoque funcionalista y nada crítico (típico de los libros de gerencia de organizaciones), el profesor Heeks ofrece en forma ordenada, ejemplos de temas que guían al lector a través de situaciones cruciales que se presentan cuando se construyen sistemas en organizaciones que se someten a estrategias de GE. El autor comienza exponiendo los diferentes enfoques que se pueden usar en la gerencia de un sistema de información en GE, a partir de allí, nos lleva al análisis de las estrategias que se siguen en su implementación, el cuidado en el manejo de los datos públicos desde la perspectiva de un sistema de información, su ciclo de vida (como cualquier otro sistema donde se involucre el desarrollo de software), el estudio de factibilidad, el análisis de la situación actual hasta lograr el diseño de una nueva propuesta de GE. 
El Dr. Heeks hace énfasis en que todo sistema de gobierno electrónico es un sistema de información y cuyo principal elemento es el dato, algo que probablemente muchos de nosotros no consideramos cuando analizamos las características funcionales del gobierno electrónico. Y esa apreciación es realmente importante porque la mayoría de los sistemas de gobierno electrónico tienen serios problemas de calidad de los datos y de su actualización. Por ello, es central desarrollar técnicas gerenciales para mejorar la calidad.

Es un libro texto, que desde el punto de vista académico, tiene el mérito principal de estar cargado de ejemplos, con diagramas ilustrativos, que resaltan escenas y situaciones de casos particulares, que se sugieren como modelos en el desarrollo de estrategias gerenciales, con ejercicios prácticos en cada capítulo, que logra reforzar en el lector el aprendizaje en el análisis operativo del diseño de sistemas de GE. Así mismo, incluye una amplia bibliografía que refuerza los conceptos y afirmaciones emitidas por el autor. Provee además un amplio material de consulta y de ejercicios adicionales que pueden ser descargados desde el sitio WEB de la editorial. Es un libro particularmente útil a todas aquellas personas que se desempeñan profesionalmente en el campo de la gerencia de los sistemas de información y, de aquellos que están dedicados a desarrollar sistemas asociados al gobierno electrónico; también es un texto útil para profesores de sistemas de información, sistemas organizacionales públicos, y estudiantes de las ciencias de la gerencia de la computación, sistemas de información y otras áreas asociadas a los tópicos gerenciales.
No es fácil analizar la brecha entre la realidad actual y los supuestos y requerimientos de un nuevo sistema de gobierno electrónico. Debido a que la mayoría de los proyectos de gobierno electrónico fallan, la evaluación de riesgo es esencial. El autor plantea que existen dos grupos de técnicas a considerar; una refiere a las guías racionales que están dirigidas a reunir datos de entrada para un eficaz ciclo de entrada-proceso-salida; y el otro grupo de técnicas, corresponde al análisis relacionado con las motivaciones personales y el impacto (frecuentemente negativo) que estas generan en la calidad de los datos, sus riesgos y la forma de mitigarlos (donde sea necesario).

Este libro es útil para el desarrollo de sistemas de gobierno electrónico que se centra en el entrenamiento del servicio, que incluye estudios de casos (de diversos puntos del planeta), diagramas instructivos, modelos sinópticos, actividades de clases, preguntas, actividades y ejercicios prácticos. Definitivamente es un libro que vale la pena consultar, si alguien se interesa en poner en funcionamiento un sistema de gobierno electrónico.

Jesús Alberto Andrade Universidad del Zulia 